\title{
Management of chronic obstructive pulmonary disease: criteria for an appropriate hospital discharge
}

\author{
Marco Candela, ${ }^{1}$ Ruggero Pastorelli, ${ }^{2}$ Antonio Sacchetta, ${ }^{3}$ Mauro Campanini, ${ }^{4}$ Leonardo M. Fabbri, ${ }^{5}$ Carlo Nozzoli ${ }^{6}$ \\ ${ }^{1}$ Department of Internal Medicine, Hospital E. Profili, Fabriano (AN); ${ }^{2}$ Department of Internal Medicine, Hospital L. Parodi Delfino, \\ Colleferro (RM); ${ }^{3}$ Department of Internal Medicine, Hospital of Conegliano (TV); ${ }^{4}$ Department of Internal Medicine, Hospital \\ Maggiore della Carità, Novara; ${ }^{5}$ Department of Oncology Haematology and Respiratory Diseases, University of Modena and \\ Reggio Emilia, Modena; ${ }^{6}$ Department of Internal Medicine, AOU Careggi, Firenze, Italy
}

\begin{abstract}
Low adherence with prescribed treatments is very common in chronic diseases and represents a significant barrier to optimal management, with both clinical and economic consequences. In chronic obstructive pulmonary disease (COPD), poor adherence, also in terms of premature discontinuation of therapy or improper use of inhaler devices, leads to increased risk of clinical deterioration. By contrast, adherence to appropriate long-term maintenance therapy is associated with improved quality of life and significantly lower risks of hospitalization and re-hospitalization, resulting in important health benefits for the individual patient and a reduction in costs for the national health services. In considering strategies to improve adherence, three main aspects should be addressed: i) patient education; ii) pharmacological alternatives and correct use of inhalers; and iii) adherence to COPD guidelines for appropriate therapy. In this field, healthcare providers play a critical role in helping patients understand the nature of their disease and its management, explaining the potential benefits and adverse effects of treatment, and teaching or checking the correct inhalation technique. These are important issues for patient management, particularly in the immediate aftermath of hospital discharge, because the high risk of re-admission is mainly due to inadequate treatment. Thus, discharge procedure should be considered a key element in the healthcare continuum from the hospital to primary care. This implies an integrated model of care delivery by all relevant health providers. In this context, we developed a structured COPD discharge form that we hope will improve the management of COPD patients, particularly in the aftermath of hospital discharge.
\end{abstract}

\section{Introduction}

In chronic diseases, poor adherence to medication regimens is unfortunately common. For example, it

Correspondence: Marco Candela, Hospital E. Profili, 60044 Fabriano (AN), Italy.

Tel. +39.0732.707235 - Fax: +39.0732 .707255 .

E-mail: marco.candela@sanita.marche.it

Key words: chronic obstructive pulmonary disease management, hospital discharge, adherence.

Contributions: MC, RR and AS conceived and designed the review; MC, LMF and $\mathrm{CN}$ critically revised the manuscript for important intellectual content.

Conflicts of interest: the authors declare no potential conflicts of interest.

Funding: the present article has received an unrestricted grant by GlaxoSmithKline S.p.A.

This work is licensed under a Creative Commons Attribution NonCommercial 3.0 License (CC BY-NC 3.0).

(C) Copyright M. Candela et al., 2013

Licensee PAGEPress, Italy

Italian Journal of Medicine 2013; 7:218-230

doi:10.4081/itjm.2013.218 has been shown that after hospitalization for acute myocardial infarction, almost one fourth of patients did not fulfill their cardiac medications even by as soon as Day 7 after discharge. ${ }^{1}$ In chronic respiratory diseases, such as asthma and chronic obstructive pulmonary disease (COPD), adherence to inhaled medications is commonly found to be rather low, i.e. below $50 \%{ }^{2,3}$ An Italian population-based retrospective study, using information obtained in 2008 from the Health Search database of the Italian College of General Practitioners, has shown that patients with asthma received only 1.54 prescribed packages of controller medication per patient per year. Also, COPD patients had only sporadic treatment, with a mean of 3.31 prescribed packages per patient per year. ${ }^{4}$ Furthermore, a recent survey in Italy carried out by the Italian polling institute (DOXA) revealed that only $25 \%$ of COPD patients use inhaled medication every day, whereas most of them use medication intermittently or as rescue medication to relieve symptoms. ${ }^{5}$ Moreover, underuse is the most common type of nonadherence in COPD subjects, although in patients over 65 years of age with polypharmacy, improper use is also frequent and possibly important. ${ }^{6}$

In general, medication adherence behavior implies both the extent to which patients take medications as prescribed by their healthcare providers (i.e. frequency and dose) and whether they continue to take a pre- 
scribed medication (persistence). Non-adherence can take many forms. It can be: i) a failure to collect the initial prescription (primary non-adherence); ii) underuse of therapy (secondary non-adherence); or iii) premature discontinuation of therapy. ${ }^{1,7}$ Also, with particular reference to COPD, non-adherence may be erratic, unintentional or intelligent. ${ }^{8}$ Erratic non-adherence occurs when the patient understands and agrees with therapy but does not consistently maintain the prescribed regimen because of carelessness or forgetfulness. Unintentional non-adherence occurs when both the patient and the healthcare provider mistakenly believe that the patient is adherent; an example may be subjects who cannot remember instructions due to cognitive impairment or depression. Intelligent non-adherence occurs when patients deliberately decide to alter or discontinue their therapy on the basis of their perception that a drug has poor efficacy or because of their fear of long-term harm.

Along with adherence to the medication scheme and persistence, also poor inhaler technique, resulting in suboptimal drug delivery, can be considered a form of non-adherence. In fact, poor compliance due to the incorrect use of pressurized metered dose inhalers (pMDIs) and dry powder inhalers (DPIs), which are the most commonly used devices in the treatment of asthma and COPD, may result in dimin- ished therapeutic effect, despite the fact that patients do carry out the treatment. ${ }^{9}$

In general, several other factors may influence adherence. Personal and individual factors may include lifestyle, psychological issues, health beliefs and behaviors, and the clinician-patient relationship. Other factors may be linked to the disease itself (progression, stability, exacerbations), or to the treatment (complexity and effectiveness of current medications, long-term therapy, costs, side-effects) (Table 1). Depression, a common co-morbidity in patients with COPD, is also known to be a potential risk factor for non-adherence, although it is seldom recognized as such. A study of the effect of demographic and psycho-social variables on medication adherence in COPD patients managed in a secondary care setting used the Health Belief Model questionnaire to define the individual's motivation for adopting health-promoting behavior. Adherence was influenced more by patients' perception of their health and medication effectiveness, depression and comorbid illness than by demographic factors or disease severity. ${ }^{10}$ So, the management of COPD is complex and requires behavioral and lifestyle changes, such as stopping smoking, adherence to exercise programs and prescribed medication regimens, comprising scheduled and as-needed medications delivered by multiple administration routes.

Table 1. Final logistical regression models predicting self-reported non-adherence.

\begin{tabular}{|c|c|c|}
\hline Variables & OR $(95 \% \mathrm{CI})$ & $\mathbf{P}$ \\
\hline \multicolumn{3}{|c|}{ Logistical regression analysis for the whole group $(n=173)$} \\
\hline $\begin{array}{l}\text { Medication effectiveness } \\
\text { Totally or most effective } \\
\text { Little or no effectiveness }\end{array}$ & $\begin{array}{c}0.094(0.017-0.517) \\
\text { Reference }\end{array}$ & $<0.01$ \\
\hline $\begin{array}{l}\text { Co-morbid illness } \\
\text { No co-morbid disease } \\
\text { Presence of co-morbid disease }\end{array}$ & $\begin{array}{l}5.02(1.0-25.2) \\
\text { Reference }\end{array}$ & $<0.05$ \\
\hline $\begin{array}{l}\text { Depression category } \\
\text { Depressed (score } 11 \text { or more) } \\
\text { Not depressed (score less than 11) }\end{array}$ & $\begin{array}{l}8.95(1.8-44.1) \\
\text { Reference }\end{array}$ & $<0.01$ \\
\hline \multicolumn{3}{|c|}{ Logistical regression analysis for the subset who answered the HBM $(n=83)$} \\
\hline $\begin{array}{l}\text { Medication effectiveness } \\
\text { Totally or most effective } \\
\text { Little or no effectiveness }\end{array}$ & $\begin{array}{c}0.082(0.015-0.46) \\
\text { Reference }\end{array}$ & $<0.01$ \\
\hline $\begin{array}{l}\text { Co-morbid illness } \\
\text { No presence of co-morbid disease } \\
\text { Presence of co-morbid disease }\end{array}$ & $\begin{array}{l}9.03(1.6-49.9) \\
\text { Reference }\end{array}$ & $<0.05$ \\
\hline $\begin{array}{l}\text { Depression category } \\
\text { Depressed (score } 11 \text { or more) } \\
\text { Not depressed (score less than 11) }\end{array}$ & $\begin{array}{l}8.77(1.8-43.8) \\
\text { Reference }\end{array}$ & $<0.01$ \\
\hline $\begin{array}{l}\text { HBM perceived barriers } \\
\text { Perceived barriers to taking medication } \\
\text { No perceived barriers }\end{array}$ & $\begin{array}{l}1.24(1.02-1.5) \\
\text { Reference }\end{array}$ & $<0.05$ \\
\hline
\end{tabular}

OR, odds ratio; CI, confidence interval; HBM, Health Belief Model questionnaire. Modified from Khdour et al., 2012.10 


\section{Methods of assessing adherence}

Adherence monitoring is an important issue especially in inhaled drug delivery. There are a number of ways to measure adherence. Each method has its strengths and limitations and none can be considered the gold standard. ${ }^{11}$

Directly observed therapy, measuring concentrations of a drug or its metabolite in blood or urine, and detection or measurement in blood of a biological marker added to the drug formulation are all examples of direct methods of measuring adherence. However, these direct approaches are expensive, impractical for routine use, and do not take into consideration the drug inhaled.

In clinical COPD settings, the easiest approach to assessing adherence is to simply ask the patient, although studies have consistently demonstrated that self-reports are inaccurate and patients generally over report medication use. ${ }^{12,13}$ Electronic monitors have been shown to be the most accurate method of assessing patients' behavior in taking medications. Results are easily quantified, but such methods are expensive and do not document whether the patient actually ingested the correct drug or dose. ${ }^{14,15}$

Although certain methods of measuring adherence may be preferred in specific clinical or research settings, a combination of measures maximizes accuracy. ${ }^{12,16}$

\section{Adherence to inhaled medication in chronic respiratory diseases and clinical outcomes}

There is no doubt that poor adherence to medication regimens represents a significant barrier to optimal management and has both clinical and economic consequences, contributing to a substantial worsening of symptoms, a higher risk of death and an increase in healthcare costs. ${ }^{6,10}$

A cross-sectional analysis of administrative healthcare data was conducted to estimate the impact of medication adherence on absenteeism and short-term disability among employees with chronic disease. ${ }^{17}$ Adherence was defined as possessing medication on at least $80 \%$ of the days during follow up. Results show that adherent employees with diabetes, hypertension, dyslipidemia, and asthma/chronic obstructive pulmonary disease had between 1.7 and 7.1 fewer days off work and between 1.1 and 5.0 fewer days on short-term disability. The highest difference between adherent and non-adherent employees in terms of absenteeism and number of days of short-term disability was observed among patients with chronic obstructive respiratory diseases. ${ }^{17}$

Under-diagnosis, under-treatment and/or poor adherence to inhaled medications lead to sub-optimal management of COPD, with an increase in the risk for acute worsening of symptoms or exacerbations. Notably, COPD exacerbations are events that deeply affect the natural course of the disease, as their frequency is associated with an accelerated decline in lung function, reduced physical activity, poorer quality of life and higher risk of death. ${ }^{18-21}$ Furthermore, acute episodes frequently lead to visits to Accident and Emergency units and hospitalizations, representing a major financial challenge for most healthcare systems. ${ }^{22,23}$ In this context, an Italian bottom-up, observational, prospective, multicenter study based on the collection of demographic, clinical, diagnostic, therapeutic and outcome data from 748 COPD patients showed that hospital admissions for exacerbations drive the costs related to the disease. Hospital admissions account for approximately $60 \%$ of the total cost of COPD management, in contrast with the modest incidence of diagnostic and treatment costs. ${ }^{23}$

Although exacerbations become progressively more frequent and troublesome as base-line lung function declines, ${ }^{18}$ results from the Evaluation of COPD Longitudinally to Identify Predictive Surrogate Endpoints (ECLIPSE) study revealed that also patients with milder disease (22\%) could be subject to frequent exacerbations and that a history of exacerbations was the most important determinant of their occurrence. This finding supports the hypothesis of a distinct phenotype, the frequent exacerbator phenotype, with intrinsic susceptibility on exposure to particular triggers. ${ }^{24}$

Taken together, the studies support the view that COPD exacerbations should be considered very severe events in the natural course of the disease, associated with cardiopulmonary complications and increased risk of mortality, supporting the definition of lung attacks. ${ }^{25-31}$

Importantly, new Global Initiative for Chronic Obstructive Lung Disease (GOLD) guidelines base the multidimensional assessment of COPD severity not only on the degree of airflow limitation, but also on future risk of exacerbations, disease progression and death using prior exacerbation history: patients with frequent or severe exacerbations (at least two episodes in the previous year or one severe exacerbation requiring hospitalization) are considered at high clinical risk independently of functional parameters. ${ }^{32}$

The frequency of acute exacerbations of COPD has been shown to be modifiable by long-term therapies capable of preventing these acute events, thus improving patient prognosis and alleviating the burden of the disease. GOLD guidelines indicate, as an option for patients with high risk of exacerbations and disease progression, the combination of inhaled corticosteroids and long-acting $\beta 2$-agonist bronchodilators, ${ }^{32}$ with additive benefits over bronchodilator alone on exacerbations, functional parameters, symptoms and quality of life. ${ }^{33-37}$ Given the importance of long-term 
maintenance therapy, a post hoc analysis of the TOwards a Revolution in COPD Health (TORCH) database was conducted in order to assess the impact of adherence on morbidity and mortality ${ }^{38}$ Results showed that good adherence, defined as an average adherence to study medications of more than $80 \%$ over the whole period the subject was in the study, was significantly associated with a $44 \%$ lower rate of severe exacerbations [rate ratio $0.56,95 \%$ confidence interval (CI): 0.48-0.65; $\mathrm{P}<0.001]$ and reduced risk of death (hazard ratio $0.40,95 \%$ CI: $0.35-0.46 ; \mathrm{P}<0.001$ ) in comparison with poor adherence $(<80 \%)$.

Also observational studies confirm the impact of adherence on clinical and pharmaco-economic outcomes. A retrospective, observational study on a centralized database considered a population of 326 COPD patients of all stages of severity. The study showed that, after 36 months of regular treatment with fluticasone/salmeterol fixed combination, lung function improved and the number of exacerbations fell. Corresponding costs and consumption of health resources [visits to the general practitioner (GP), use of systemic steroids and antibiotics] also decreased in agreement with these trends. ${ }^{39}$ A study of a Medicare population shows that COPD patients with higher adherence to prescribed regimens experienced fewer hospitalizations and lower costs than those who exhibited lower adherence behaviors. ${ }^{40}$

Furthermore, discontinuation of the steroid component of the combination has been shown to worsen patient's clinical condition. In randomized, doubleblind, multicenter trials, withdrawing fluticasone in patients with COPD who had been receiving salmeterol/fluticasone propionate twice daily resulted in acute and persistent deterioration in lung function and dyspnea and in an increase in the number of exacerbations and in the percentage of disturbed nights. ${ }^{41-43}$ These results clearly indicate a key role for inhaled steroids combined with bronchodilators in the management of COPD as their discontinuation leads to disease deterioration, even under treatment with a long-acting $\beta$-adrenoceptor agonist. Thus, improving adherence to long-term maintenance therapy is essential for patient control of the disease and symptoms, and for reducing healthcare costs.

\section{How to improve adherence to long-term maintenance therapy in chronic obstrictive pulmonary disease}

Adherence to inhaled therapy in COPD within the context of a clinical trial is generally good and associated with improved outcomes. ${ }^{38}$ However, this scenario does not reflect real-life patient behavior. Studies have estimated that chronic respiratory diseases are associated with particularly high rates of cost-related medication non-adherence. ${ }^{14,44,45}$ In Italy, poor adherence to inhaled medications is estimated to cause a $20 \%$ increase in the risk of COPD exacerbations and a $50 \%$ increase in healthcare costs $(2723$ euro/patient/year). ${ }^{5}$

When considering strategies to improve adherence in chronic respiratory disease medication, four main aspects should be addressed: patient education, pharmacological interventions, correct use of inhalers, and adherence to COPD guidelines for appropriate therapy. Since patients are more likely to adhere to treatment when they believe it will improve disease management or control, healthcare providers play a critical role in patient education. They can help patients understand the nature of their disease and the potential benefits of treatment. They can also address concerns regarding potential adverse effects and encourage patients to develop self-management skills. ${ }^{13,46}$ Cecere et al ${ }^{46}$ identified patient perception of clinician expertise in lung disease as the strongest predictor of adherence to maintenance therapies. Clinicians who are confident in their ability to treat COPD may also appear to be more skilled and knowledgeable to their patients, thus having a positive impact on their belief of the effectiveness of the prescribed treatment. For this reason, the term concordance has been proposed to replace the definition of adherence as the therapeutic alliance between patients and healthcare professionals regarding a therapeutic course of action. ${ }^{3}$

Studies on the influence of patient education on adherence and self-management in COPD are limited and have yielded mixed findings. ${ }^{47-51}$ Positive results come from a controlled randomized study by Gallefoss et $a l^{47}$ showing that patients in the education group were dispensed less than half the amount of rescue medication given to the control group and decreased the need for general practitioner visits during the 1-year follow up by $85 \%$ (from 3.4 to 0.5 visits; $\mathrm{P}<0.001$ ).

On the other hand, improved adherence is not sufficient if inhalation devices are being used incorrectly. Despite advancements in technology, evidence from the literature demonstrates that a large number of patients are unable to use their inhalers properly, with a consequent reduction in therapeutic benefit. ${ }^{52-54}$ Based on a real-life setting, it has been reported that $76 \%$ of patients using a pMDI make at least one error when using their inhaler, mostly due to lack of actuation-inhalation co-ordination or stopping inhalation for the cold freon effect. ${ }^{54}$ In addition, between $4 \%$ and $94 \%$ of patients do not use a DPI correctly and $25 \%$ have never received inhaler-technique training. ${ }^{54}$ Thus, not all inhalation devices are appropriate for all patients and it is important to prescribe a device that the patient can and will use effectively at home.

Since poor inhalation technique has detrimental 
consequences for clinical efficacy, regular assessment and reinforcement of correct inhalation technique by health professionals and caregivers is an essential component of successful disease management. A comparison of two multicenter, cross-sectional, observational surveys on large samples of Italian patients experienced in the use of the most commonly prescribed inhalers found high rates of device mishandling (from $17 \%$ to $43 \%$ ). Education by healthcare providers was the only modifiable factor associated with a reduction in misuse. ${ }^{55}$

On the basis of these observations, a joint task force of multidisciplinary experts on the delivery of pharmaceutical aerosols was approved by the European Respiratory Society (ERS) and the International Society for Aerosols in Medicine (ISAM). This aimed to draw up clear, up-to-date recommendations that enable the pulmonary physician to choose the type of aerosol delivery device that is most suitable for their patients at home and in hospital. ${ }^{54}$ These recommendations include the training of the patient in the correct use of the device and the evaluation of the patients' inhalation technique to be sure they are using the devices properly. Accordingly, the Italian Society of Allergists, together with the Italian Society of Respiratory Physicians (AAITO-SIAIC-SIMeR), published a statement on adherence to inhalation therapy, underlining the fact that an unmotivated switch to new devices without appropriate patient education has been reported to increase the risk of clinical deterioration. ${ }^{56}$

A further obstacle to achieving substantial therapeutic advantages in the management of COPD is represented by poor knowledge and implementation of international guidelines. Many patients with COPD, despite having symptoms of dyspnea, are not being treated. A study carried out in Italy in 2002 showed that one-third of the COPD patients discharged from hospital when the exacerbation had resolved had never been diagnosed and treated, even though $83 \%$ of them had moderate-to-very-severe COPD and approximately $30 \%$ already had respiratory failure. Only $20 \%$ had received information about the nature of the disease and none had received a written action plan. ${ }^{57} \mathrm{In}$ order to address this, a big effort was made within the scientific community to implement and make more widespread a shared evidence-based approach.

Pharmacists may also help patients successfully manage their chronic obstructive pulmonary disease to achieve optimal therapeutic outcomes. For example, in elderly patients with sufficient cognitive function and manual dexterity, the pharmacist's knowledge of appropriate inhaler technique, patient education and follow-up assessment have been reported to optimize device competency and medication adherence. ${ }^{58}$

Furthermore, several studies have shown the role of the nurse practitioner in improving COPD patient care by being aware of all the issues affecting correct inhaler use, in order to provide optimum education to patients, caregivers, and other healthcare providers. ${ }^{59}$

\section{Maintenance therapy after hospital discharge prevents re-admission}

Exacerbations tend to cluster together in time. Hurst and colleagues reported that approximately one-third of exacerbations reoccurred once and that over a quarter of first exacerbations were followed by a second exacerbation within eight weeks. ${ }^{60}$ Similarly, a history of exacerbations in the previous year is predictive of exacerbations in the current year. ${ }^{24}$ Thus, since in the months after an exacerbation-related hospitalization the risk of re-admission is high, ${ }^{61-64}$ it is crucial for patients not on treatment to start maintenance therapy.

This question has been addressed in real-life studies. Dal Negro et al. ${ }^{23}$ carried out a prospective study to estimate the consumption of healthcare resources and costs generated in one year by a population of patients with COPD in a real-life setting. They reported a significant reduction in the total mean cost per patient $(-21.7 \%)$ compared to baseline. This was attributable to a more appropriate therapeutic intervention during follow up. The increase in the cost of pharmaceutical drugs (both principal therapy and that for concomitant diseases) was sharply overtaken by a net decrease in visits to GPs and specialists, use of emergency structures, hospitalization, days off work, and use of alternative therapies. In general, the data confirm that a careful and appropriate use of the therapeutic resources currently available represents the key point on which to base the management of COPD. Stuart et al. compared users and non-users of maintenance medication in a nationally representative sample of Medicare beneficiaries with COPD on 3 claimsbased outcomes: any hospitalization, any re-hospitalization within 31 days, and total annual Medicare expenditures. ${ }^{65}$ Maintenance drug users were less likely to be hospitalized [odds ratio (OR): $0.70 ; 95 \%$ CI: 0.61-0.79) or re-hospitalized (OR: 0.74; 95\% CI: $0.63-0.87)$ than non-users, and had significantly lower annual Medicare expenditures (-\$3916; 95\% CI: \$4977 to $-\$ 2854$ ).

Comparable results have been reported by Soriano et al. in a retrospective cohort analysis of the UK General Practice Research Database. ${ }^{66}$ Re-hospitalizations for a COPD-related medical condition or death within one year after the first hospitalization in 3636 COPD patients receiving maintenance therapy with inhaled corticosteroids or long-acting $\beta 2$-agonists were compared with 627 reference patients with COPD who were prescribed only short-acting bronchodilators. The risk of re-hospitalization or death was reduced by $10 \%$ in users of long-acting $\beta 2$-agonists only (not significant), 
by $16 \%$ in users of inhaled corticosteroids only, and by $41 \%$ in users of combined inhaled corticosteroids and long-acting $\beta 2$-agonists (both $\mathrm{P}<0.05$ ) (Figure 1). ${ }^{66}$

Further data to support the role of maintenance combination therapy come from a recent observational, retrospective study on two matched cohorts of patients who received fluticasone propionate/salmeterol combination as new therapy or anticholinergic bronchodilators (tiotropium or ipratropium) within 30 days of an initial COPD-related hospitalization or Emergency Department visit. The proportions of patients with COPD-related healthcare events, the mean event rates, and the mean costs in the subsequent 12 months were calculated. Results showed that COPD patients who received new maintenance therapy with the combination fluticasone/salmeterol had significantly fewer COPD-related re-hospitalizations following an exacerbation compared to patients with new or continuing therapy with anticholinergics. COPD-related healthcare costs were lower for the combination cohort, even though prescription drug costs for this cohort were higher. Savings from lower medical costs more than offset the higher drug costs. ${ }^{67}$

One important issue that has not been addressed properly is the complexity of COPD exacerbations.
This may be due to infections or exposure to irritants of the respiratory system (exacerbations of COPD) but also by exacerbations of concomitant respiratory (e.g. asthma, bronchiectasis, pneumonia) and/or non-respiratory (arrhythmias, heart failure, ischemic heart disease, thromboembolism, etc.) conditions. ${ }^{68-70}$ Thus other causes of exacerbations of respiratory symptoms must be considered and appropriately treated in the aftermath of hospital discharge.

\section{Appropriate hospital discharge and follow up}

While the exact number of avoidable readmissions is unknown, a systematic review of 34 studies, most based on retrospective chart review, found that between $5 \%$ and $79 \%$ of readmissions were likely to be preventable. ${ }^{71}$ Re-admissions within a few days (3-7 days) may suggest inadequate in-hospital care, or an inadequate hospital discharge, and/or poor co-operation between hospital and primary care providers.

Thus, patient discharge is not a simple administrative procedure, but a key element in the healthcare continuum from the hospital to primary care, which implies an integrated model of care delivery by all rel-

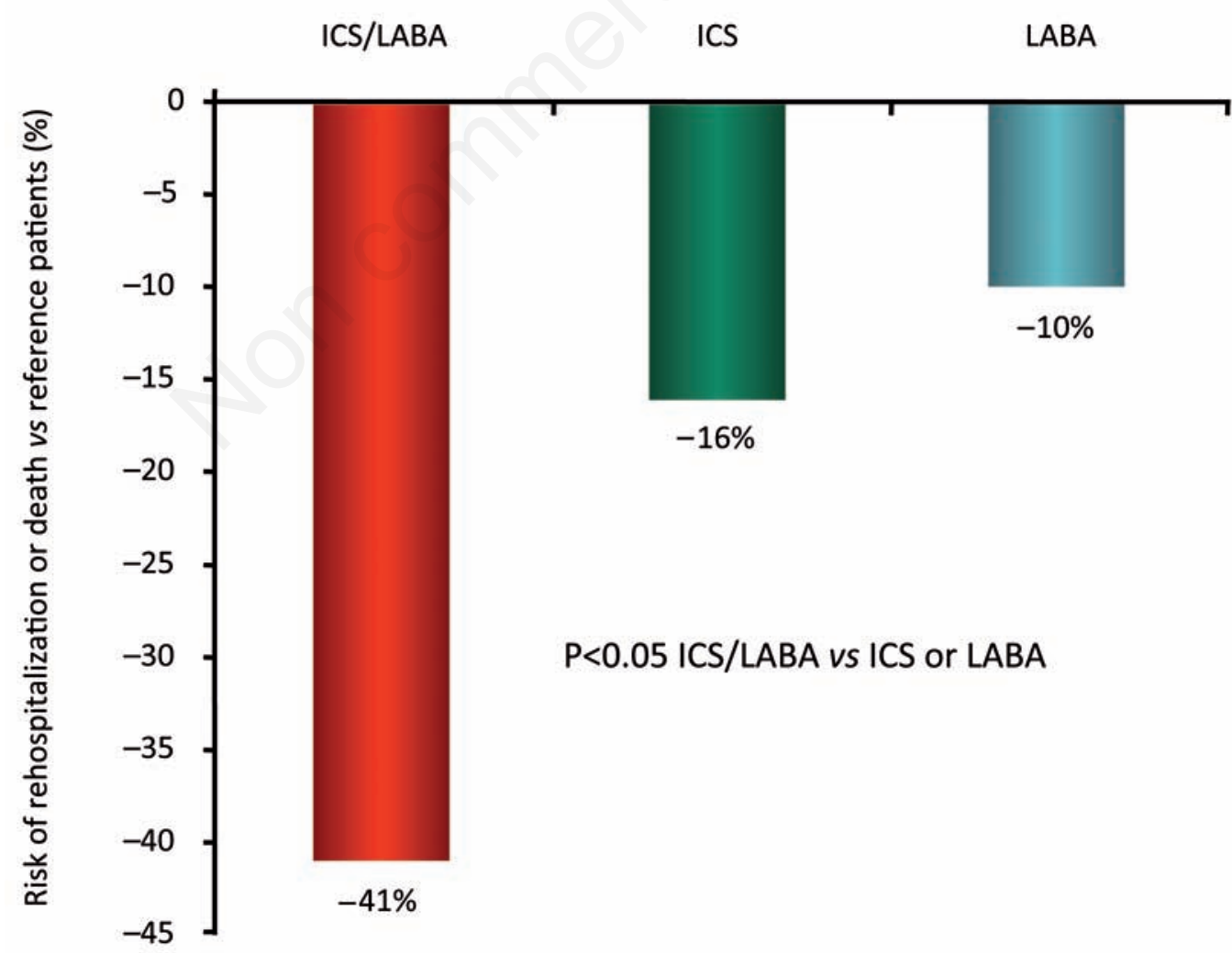

Figure 1. Retrospective cohort analysis of chronic obstructive pulmonary disease (COPD)-related rehospitalization or death within one year of first hospitalization in 3636 COPD patients receiving inhaled corticosteroids (ICS)and/or longacting $\beta$-agonists (LABA) compared with 627 reference patients receiving LABA alone. Adapted from Soriano et al., $2003 .{ }^{66}$ 
evant healthcare providers. These observations suggest the possibility of defining an evidence-based package of care for COPD patients at discharge following a lung attack. This would allow an optimal standard of care to be developed. This could be structured in a hospital discharge form including reporting discharge criteria and a checklist of items to assess at time of discharge from hospital and at follow-up visits, as also indicated in GOLD guidelines. ${ }^{32}$

In this context, a COPD Hospital Discharge Form (Annex 1) has been developed by a national board of the Italian Federation of Associations of Hospital Doctors on Internal Medicine (FADOI), sharing a proposal implemented by FADOI associates in Lazio, Central Italy, and the indications coming from the last two consensus conferences in the course of the annual FADOI national meeting, as a tool for appropriate hospital discharge and follow up, and also including an information leaflet for COPD patients (Annex 2).

\section{Conclusions}

Adherence to appropriate long-term maintenance therapy in COPD patients has been shown to be associated with significantly lower risks of hospitalization and re-hospitalization. This has resulted in an important health benefit for the individual patient, a reduction in costs, and a lowering of the financial burden for the national health services. Hospital discharge is a key process in healthcare continuum from the hospital to primary care. Therefore, the implementation of tools for appropriate hospital discharge and follow up is of fundamental importance in the management of COPD.

\section{References}

1. Rand CS. Patient adherence with COPD therapy. Eur Respir Rev 2005;14:96-101.

2. Horne R. Compliance, adherence, and concordance: implications for asthma treatment. Chest 2006;130:65S-72S.

3. Restrepo RD, Alvarez MT, Wittnebel LD, et al. Medication adherence issues in patient treated for COPD. Int $\mathrm{J}$ Chron Obstruct Pulmon Dis 2008;3:371-84.

4. Cazzola M, Segreti A, Bettoncelli G, et al. Change in asthma and COPD prescribing by Italian general practitioners between 2006 and 2008. Resp Med 2011;20: 291-8.

5. SIMER-SIAIC-AAITO. Aderenza del paziente alla terapia, Milano Jan 13, 2013 (oral presentation). Respiro Primavera 2013:6-8. Available from: http://www. aaito.it/documenti/comunicati/STATEMENT_AAITOSIAIC-SIMeR.pdf [In Italian].

6. Steinman MA, Landefeld CS, Rosenthal GE, et al. Polypharmacy and prescribing quality in older people. J Am Geriatr Soc 2006;54:1516-23.

7. Lareau SC, Yawn BP. Improving adherence with inhaler therapy in COPD. Int J Chron Obstruct Pulmon Dis 2010;5:401-6.

8. Bourbeau J, Bartlett SJ. Patient adherence in COPD. Thorax 2008;63:831-8.

9. Lavorini F, Magnan A, Dubus JC, et al. Effect of incorrect use of dry powder inhalers on management of patients with asthma and COPD. Resp Med 2008;102: 593-604.

10. Khdour MR, Hawwa AF, Kidney JC, et al. Potential risk factors for medication non-adherence in patients with chronic obstructive pulmonary disease (COPD). Eur J Clin Pharmacol 2012;68:1365-73.

11. Osterberg L, Blaschke T. Adherence to Medication. N Engl J Med 2005;353:487-97.

12. Di Matteo MR. Variations in patients' adherence to medical recommendations: a quantitative review of 50 years of research. Med Care 2004;42:200-9.

13. Barnestein-Fonseca P, Leiva-Fernández J, Vidal-España $\mathrm{F}$, et al. Is it possible to diagnose the therapeutic adherence of patients with COPD in clinical practice? A cohort study. BMC Pulm Med 2011;11:6.

14. Denyer J. Adherence monitoring in drug delivery. Expert Opin Drug Deliv 2010;7:1127-31.

15. Jentzsch NS, Carmagos PA, Colosimo EA, et al. Monitoring adherence to beclomethasone in asthmatic children and adolescents through four different methods. J Allergy 2009;64:1458-62.

16. Liu H, Golin CE, Miller LG, et al. A comparison study of multiple measures of adherence to HIV protease inhibitors. Ann Intern Med 2001;134:968-77.

17. Carls GS, Roebuck MC, Brennan TA, et al. Impact of medication adherence on absenteeism and short-term disability for five chronic diseases. J Occup Environ Med 2012;54:792-805.

18. Donaldson GC, Seemungall TAR, Bhowmik A, Wedzicha JA. Relationship between exacerbation frequency and lung function decline in chronic obstructive pulmonary disease. Thorax 2002;57:847-52.

19. Almagro P, Calbo E, Ochoa de Echaguen A, et al. Mortality after hospitalization for COPD. Chest 2002;121: 1441-8.

20. Groenewegen KH, Schols AMWJ, Wouters E. Mortality and mortality-related factors after hospitalization for acute exacerbation of COPD. Chest 2003;124:459-67.

21. Soler-Cataluna JJ, Martinez-Garcia MA, Roman Sanchez P, et al. Severe acute exacerbations and mortality in patients with chronic obstructive pulmonary disease. Thorax 2005;60:925-31.

22. Donner CF, Virchow JC, Lusuardi M. Pharmacoeconomics in COPD and inappropriateness of diagnostics, management and treatment. Resp Med 2011;105:828-37.

23. Dal Negro R, Toghella S, Tosatto R, et al. Costs of chronic obstructive pulmonary disease (COPD) in Italy: The SIRIO study (Social Impact of Respiratory Integrated Outcomes). Resp Med 2008;102:92-101.

24. Hurst, JR, Vestbo J, Anzueto A, et al. Susceptibility to exacerbation in chronic obstructive pulmonary disease. N Engl J Med 2010;363:1128-38.

25. Donaldson GC, Hurst JR, Smith CJ, et al. Increased risk of myocardial infarction and stroke following exacerbation of COPD. Chest 2010;137:1091-7.

26. Høiseth AD, Neukamm A, Karlsson BD, et al. Elevated high-sensitivity cardiac troponin $\mathrm{T}$ is associated with in- 
creased mortality after acute exacerbation of chronic obstructive pulmonary disease. Thorax 2011;66:775-81.

27. Chang CL, Robinson SC, Mills GD, et al. Biochemical markers of cardiac dysfunction predict mortality in acute exacerbations of COPD. Thorax 2011;66:764-8.

28. Maclay JD, McAllister DA, Johnston S, et al. Increased platelet activation in patients with stable and acute exacerbation of COPD. Thorax 2011;66:769-74.

29. Bhatt SP, Nanda S, Kintzer JS. Arrhythmias as trigger for acute exacerbations of chronic obstructive pulmonary disease. Resp Med 2012;106:1134-8.

30. Fabbri LM, Beghé B, Agusti A. Cardiovascular mechanisms of death in severe COPD exacerbation: time to think and act beyond guidelines. Thorax 2011;66:745-7.

31. Fitzgerald MJ. Targeting lung attack. Thorax 2010;66: 365-6.

32. Global Initiative for Chronic Obstructive Lung Disease (GOLD). Guidelines for the assessment of COPD severity. Global Initiative for Chronic Obstructive Lung Disease. Update 2013. Available from: http://www. goldcopd.org/uploads/users/files/GOLD_Report_2013 Feb20.pdf

33. Calverly PMA, Anderson JA, Celli B, et al. Salmeterol and fluticasone propionate and survival in chronic obstructive pulmonary disease. N Engl J Med 2007;356: 775-89.

34. Celli BR, Thomas NE, Anderson JA, et al. Effect of pharmacotherapy on rate of decline of lung function in COPD: results from the TORCH study. Am J Respir Crit Care Med 2008;178:332-8.

35. Jenkins CR, Jones PW, Calverly PMA, et al. Efficacy of salmeterol/fluticasone propionate by GOLD stage of chronic obstructive pulmonary disease: analysis from the randomised, placebo-controlled TORCH study. Resp Res 2009;10:59-63.

36. Kardos P, Wencker M, Glaab T, Vogelmeier C. Impact of salmeterol/fluticasone propionate versus salmeterol on exacerbations in severe chronic obstructive pulmonary disease. Am J Respir Crit Care Med 2007;175: 144-9.

37. Szafranski W, Cukier A, Ramirez A. Efficacy and safety of budesonide/formoterol in the management of chronic obstructive pulmonary disease. Eur Respir J 2003;21:7481.

38. Vestbo J, Anderson JA, Calverley PM, et al. Adherence to inhaled therapy, mortality and hospital admission in COPD. Thorax 2009;64:939-43.

39. Dal Negro RW, Bonadiman L, Micheletto C, et al. Longterm salmeterol/fluticasone propionate treatment in COPD: 3-year clinical and pharmacoeconomic outcome. Multidiscip Resp Med 2010;5:250-8.

40. Simoni-Wastila L, Wei YJ, Qian J, et al. Association of chronic obstructive pulmonary disease maintenance medication adherence with all-cause hospitalization and spending in a Medicare population. Am J Geriatr Pharmacother 2012;10:201-10.

41. Wouters EFM, Postma DS, Fokkens B, et al. Withdrawal of fluticasone propionate from combined fluticasone/ salmeterol treatment in patients with COPD causes immediate and sustained disease deterioration: a randomised controlled trial. Thorax 2005;60:480-7.

42. Anzueto A, Ferguson JT, Feldman G, et al. Effect of fluticasone propionate/salmeterol (250/50) on COPD ex- acerbations and impact on patient outcome. COPD 2009;6:320-9.

43. Ferguson JT, Anzueto A, Fei R, et al. Effect of fluticasone propionate/salmeterol $(250 / 50 \mu \mathrm{g})$ or salmeterol (50 $\mu \mathrm{g})$ on COPD exacerbations. Resp Med 2008;102: 1099-108.

44. Madden JM, Graves AJ, Zhang F, et al. Cost-related medication non adherence and spending on basic needs following implementation of Medicare Part D. JAMA 2008;299:1922-8.

45. Castaldi PJ, Rogers WH, Gelb Safran D, et al. Inhaler costs and medication non adherence among seniors with chronic pulmonary disease. Chest 2010;138:614-20.

46. Cecere LM, Slatore CG, Uman JE, et al. Adherence to long-acting inhaled therapies among patients with chronic obstructive pulmonary disease (COPD). COPD 2012;9:251-8.

47. Gallefoss F. The effects of patient education in COPD in a year follow-up randomised, controlled trial. Patient Educ Couns 2004;52:259-66.

48. Worth H, Dhein Y. Does patient education modify behaviour in the management of COPD? Patient Educ Couns 2004;52:267-70.

49. Hesselink AE, Penninx BW, van der Windt DA, et al. Effectiveness of an education programme by a general practice assistant for asthma and COPD patients: results from a randomised controlled trial. Patient Educ Couns 2004;55:121-8.

50. Monninkhof E, van der Valk P, van der Palen J, et al. Effects of a comprehensive self-management programme in patients with chronic obstructive pulmonary disease. Eur Respir J 2003;22:815-20.

51. Monninkhof E, van der Valk P, van der Palen J, et al. Self management education for patients with chronic obstructive pulmonary disease: a systematic review. Tho$\operatorname{rax} 2003 ; 58: 394-8$.

52. Roy A, Battle K, Lurslurchachai L, et al. Inhaler device, administration technique, and adherence to inhaled corticosteroids in patients with asthma. Prim Care Respir J 2011;20:148-54.

53. Melani AS, Bonavia M, Cilenti V, et al. Inhaler mishandling remains common in real life and is associated with reduced disease control. Resp Med 2011;105:930-8.

54. Laube BL, Janssens HM, de Jongh FHC, et al. What the pulmonary specialist should know about the new inhalation therapies. ERS/ISAM Task Force Report. Eur Respir J 2011;37:1308-31.

55. Zagà V, Mariano V, Vakeffliu J, et al. Is inhaler technique improving in Italy? Rassegna di Patologia dell'Apparato Respiratorio 2012;27:211-8.

56. The Italian Society of Allergists and the Italian Society of Respiratory physicians (AAITO-SIAIC-SIMeR). Statement on adherence to inhalation therapy. Available from: http://www.aaito.it/documenti/comunicati/ STATEMENT AAITO-SIAIC-SIMeR.pdf

57. Zoia MC, Corsico AG, Beccaria M, et al. Exacerbations as a starting point of pro-active chronic obstructive pulmonary disease management. Resp Med 2005;9:156875 .

58. Barrons R, Pegram A, Borries A. Inhaler device selection: special considerations in elderly patients with chronic obstructive pulmonary disease. Am J Health Syst Pharm 2011;68:1221-32. 
59. Lareau SC, Hodder R. Teaching inhaler use in chronic obstructive pulmonary disease patients. J Am Acad Nurse Pract 2012;24:113-20.

60. Hurst JR, Donaldson GC, Quint TK, et al. Temporal clustering of exacerbations in chronic obstructive pulmonary disease. Am J Respir Crit Care Med 2009;179: 369-74.

61. Almagro P, Barreiro B, Ochoa de Echaguen A, et al. Risk factors for hospital readmission in patients with chronic obstructive pulmonary disease. Respiration 2006;73:311-7.

62. Bahadori K, Fitzgerald JM. Risk factors of hospitalization and readmission of patients with COPD exacerbation - a systematic review. Int J Chron Obstruct Pulmon Dis 2007;2:241-51.

63. Bahadori K, Fitzgerald JM, Levy RD, et al. Risk factors and outcomes associated with chronic obstructive pulmonary disease exacerbations requiring hospitalizations. Can Respir J 2009;16:e43-9.

64. Terzano C, Conti V, Di Stefano F, et al. Comorbidity, hospitalization, and mortality in COPD: results from a longitudinal study. Lung 2010;188:321-9.

65. Stuart BC, Simoni-Wastila L, Zuckerman IH. Impact of maintenance therapy on hospitalization and expendi- tures for Medicare beneficiaries with chronic obstructive pulmonary disease. Am J Geriatric Pharmather 2010;8: 441-53.

66. Soriano JB, Kiri VA, Pride NB, Vestbo J. Inhaled corticosteroids with/without long-acting beta-agonists reduce the risk of rehospitalization and death in COPD patients. Am J Respir Med 2003;2:67-74.

67. Dalal AA, Shah M, D’Souza AO, Crater GD. Rehospitalization risks and outcomes in COPD patients receiving maintenance pharmacotherapy. Resp Med 2012;106: 829-37.

68. Beghè B, Verduri A, Roca M, Fabbri LM. Exacerbation of respiratory symptoms in COPD patients may not be exacerbations of COPD. Eur Resp J 2013;41:993-5.

69. Roca M, Verduri A, Corbetta L, et al. Mechanisms of acute exacerbation of respiratory symptoms in chronic obstructive pulmonary disease. Eur J Clin Invest 2013; 43:510-21.

70. Nozzoli C, Beghè B, Boschetto P, Fabbri LM. Need to identify and treat COPD in cardiac patients. Chest 2013. [In press].

71. van Walraven C, Bennett C, Jennings A, et al. Proportion of hospital readmissions deemed avoidable: a systematic review. CMAJ 2011;183:E391-402. 


\section{Annex 1}

FADOI proposal for a Hospital Discharge Form for patients with chronic obstructive pulmonary disease

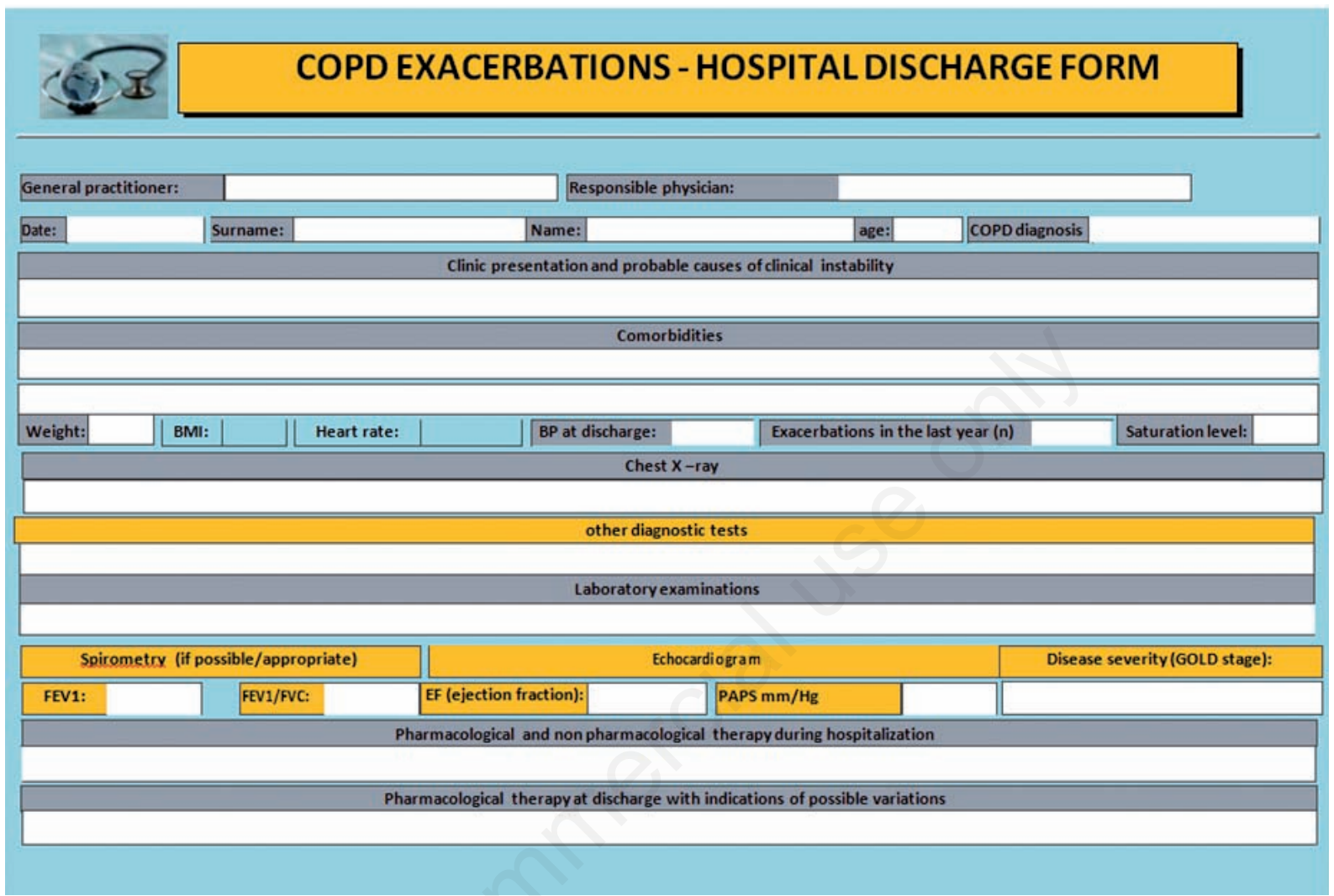

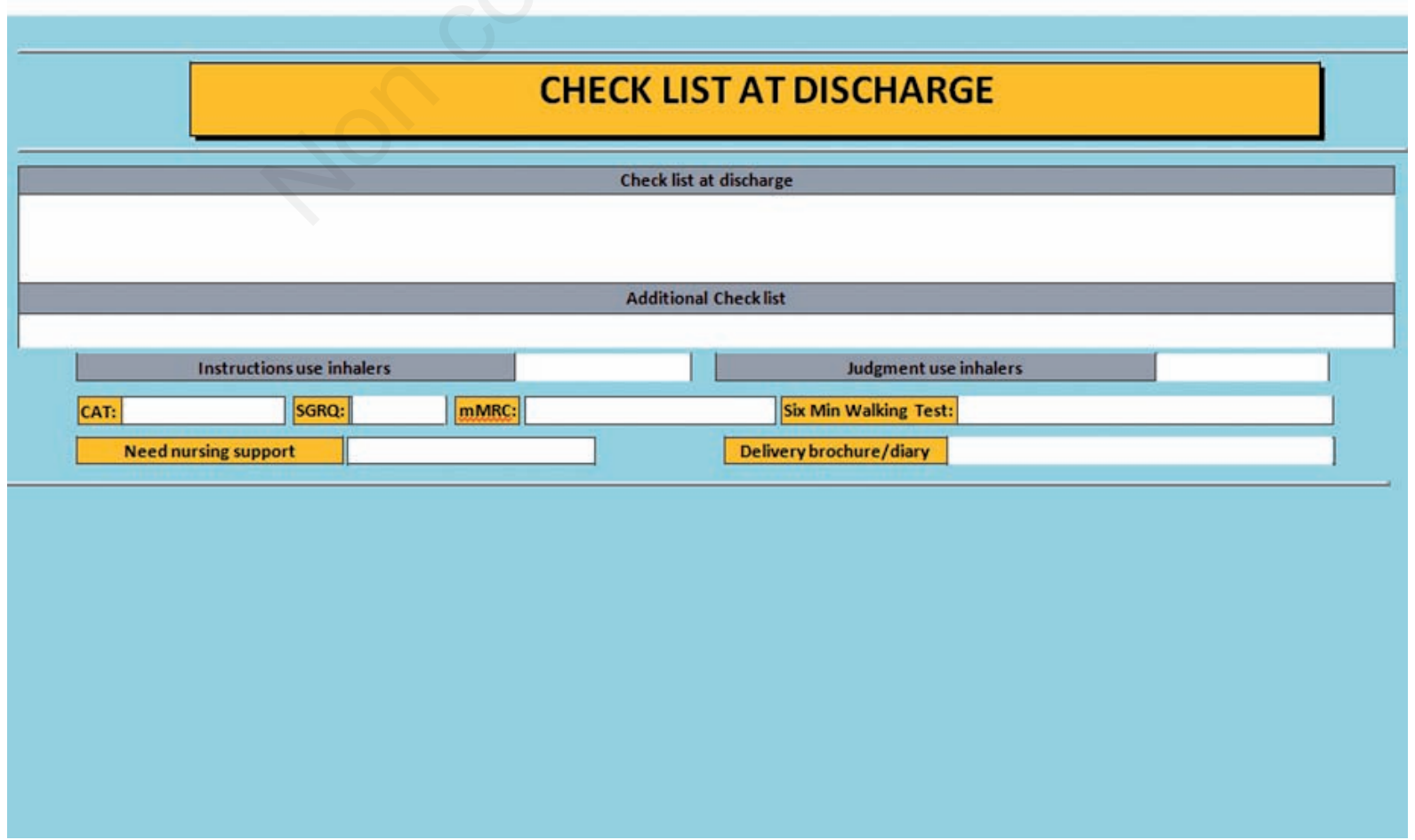




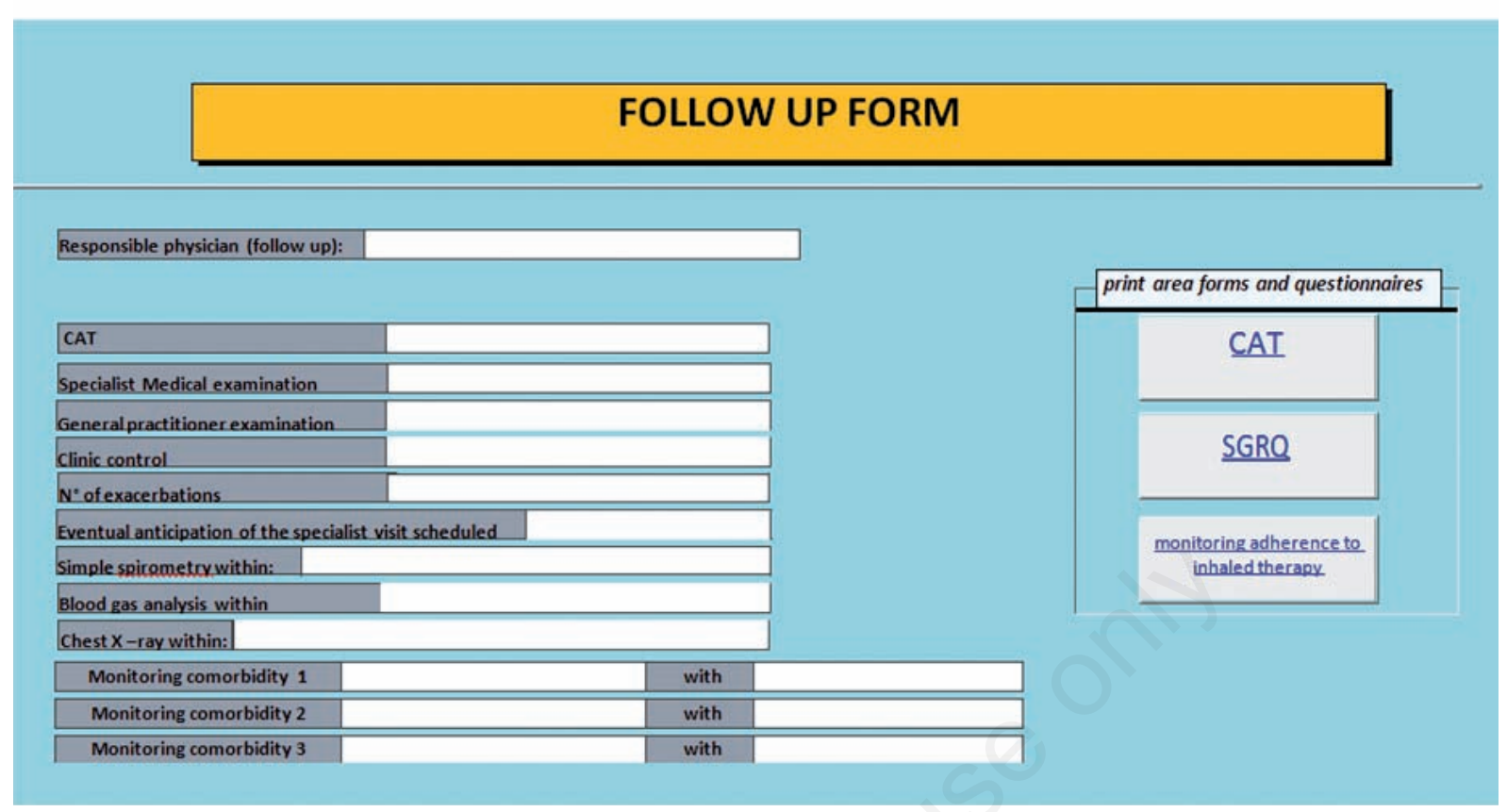

Report any omissions of employment (therapy A and therapy B)

\begin{tabular}{|c|c|c|c|c|c|c|c|c|c|c|c|c|c|c|}
\hline & \multicolumn{14}{|c|}{ month } \\
\hline & \multicolumn{2}{|c|}{ mon } & \multicolumn{2}{|c|}{ tue } & \multicolumn{2}{|c|}{ wed } & \multicolumn{2}{|c|}{ thu } & \multicolumn{2}{|c|}{ Fri } & \multicolumn{2}{|c|}{ Sat } & \multicolumn{2}{|c|}{ Sun } \\
\hline & morning & evening & morning & evening & morning & evening & morning & evening & morning & evening & morning & evening & morning & evening \\
\hline \multicolumn{15}{|l|}{ week 1} \\
\hline \multicolumn{15}{|l|}{ week 2} \\
\hline \multicolumn{15}{|l|}{ week 3} \\
\hline week 4 & & & & & & & & & & & & & & \\
\hline
\end{tabular}

\begin{tabular}{|c|c|c|c|c|c|c|c|c|c|c|c|c|c|c|}
\hline & \multicolumn{14}{|c|}{ month } \\
\hline & \multicolumn{2}{|c|}{ mon } & \multicolumn{2}{|c|}{ tue } & \multicolumn{2}{|c|}{ wed } & \multicolumn{2}{|c|}{ thu } & \multicolumn{2}{|c|}{ Fri } & \multicolumn{2}{|c|}{ Sat } & \multicolumn{2}{|c|}{ Sun } \\
\hline & morning & evening & morning & evening & morning & evening & morning & evening & morning & evening & morning & evening & morning & evening \\
\hline \multicolumn{15}{|c|}{ 每 } \\
\hline \multicolumn{15}{|l|}{ week 2} \\
\hline \multicolumn{15}{|l|}{ week 3} \\
\hline week 4 & & & & & & & & & & & & & & \\
\hline
\end{tabular}

\begin{tabular}{|c|c|c|c|c|c|c|c|c|c|c|c|c|c|c|}
\hline & \multicolumn{14}{|c|}{ month. } \\
\hline & \multicolumn{2}{|c|}{$\begin{array}{l}\text { mon } \\
\end{array}$} & \multicolumn{2}{|c|}{ tue } & \multicolumn{2}{|c|}{ wed } & \multicolumn{2}{|c|}{ thu } & \multicolumn{2}{|c|}{ Fri } & \multicolumn{2}{|c|}{ Sat } & \multicolumn{2}{|c|}{ Sun } \\
\hline & morning & evening & morning & evening & morning & evening & morning & evening & morning & evening & morning & evening & morning & evening \\
\hline \multicolumn{15}{|c|}{ 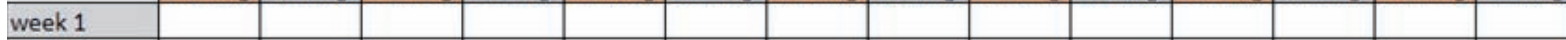 } \\
\hline \multicolumn{15}{|l|}{ week 2} \\
\hline \multicolumn{15}{|l|}{ week 3} \\
\hline week 4 & & & & & & & & & & & & & & \\
\hline
\end{tabular}

\begin{tabular}{|c|c|c|c|c|c|c|c|c|c|c|c|c|c|c|}
\hline & \multicolumn{14}{|c|}{ month } \\
\hline & \multicolumn{2}{|c|}{ mon } & \multicolumn{2}{|c|}{ tue } & \multicolumn{2}{|c|}{ wed } & \multicolumn{2}{|c|}{ thu } & \multicolumn{2}{|c|}{ Fri } & \multicolumn{2}{|c|}{ Sat } & \multicolumn{2}{|c|}{ Sun } \\
\hline & morning & evening & morning & evening & morning & evening & morning & evening & morning & evening & morning & evening & morning & evening \\
\hline \multicolumn{15}{|c|}{ 年 } \\
\hline \multicolumn{15}{|l|}{ week 2} \\
\hline \multicolumn{15}{|l|}{ week 3} \\
\hline week 4 & & & & & & & & & & & & & & \\
\hline
\end{tabular}




\section{Annex 2}

\section{A FADOI information leaflet for the chronic obstructive pulmonary disease patient}

\section{What is chronic obstructive pulmonary disease?}

Chronic obstructive pulmonary disease (COPD) is a serious disease that over time makes it hard to breathe and affects lungs and airways. COPD is a comprehensive term used for a number of different clinical conditions including chronic bronchitis and emphysema. It is rather common, but many people who have COPD don't know it. COPD is characterized by chronic respiratory symptoms, mainly dyspnea that may or may not be associated with chronic cough and sputum. Chronic respiratory symptoms are often exacerbated in COPD patients by infections or by exposure to irritants (exacerbations of COPD) but also by exacerbations of concomitant respiratory (e.g. asthma, pneumonia) and/or non-respiratory diseases. These COPD exacerbations occur particularly in a sub-group of patients with COPD, but are of importance because they may require use of antibiotics and/or steroids or drugs for concomitant diseases (e.g. anticoagulants, diuretics, antiarrhythmic agents, etc.) and also may require admission to hospital. Exacerbations often re-occur in the aftermath of hospital discharge, mainly because of inadequate treatment of both respiratory and non-respiratory triggers. Thus all causes of exacerbations of respiratory symptoms must be considered and appropriately treated in the aftermath of hospital discharge.

\section{Plan}

The main symptoms of COPD to look out for are shortness of breath and a cough that you can't get rid of, both of which may get worse during winter, together with sputum. Simple everyday tasks, such as climbing the stairs or trying to walk at the same pace as your family and friends, can become difficult. As the disease progresses, you can find it difficult to get about without becoming severely short of breath.

You may dismiss these symptoms as a result of being out of shape, getting older, or just a smoker's cough, but they could be an early indication of COPD. If you recognize any of these symptoms, it is important for you to consult your physician: the symptoms are generally treatable.

If you are diagnosed with COPD, your doctor will talk to you about how you can live with the disease.

\section{Do}

Stopping smoking is an essential therapeutic measure and this should be promoted through counseling and psychological support, bearing in mind that more complex interventions with pharmacological support have higher rates of failure than abstinence from smoking.

Annual flu vaccination and pneumococcal vaccination are recommended for all patients with COPD.

The pneumococcal vaccination should be done at least once in patients with COPD and may be repeated in those at greatest risk; young patients with significant changes in lung function should also be vaccinated.

For the moment there is not enough evidence for using an antibiotic prophylaxis in stable COPD and there is insufficient evidence to recommend a therapy with antioxidants, immunostimulants, or mucolytics.

\section{Check}

Use this checklist to help you decide if you should visit your doctor or nurse.

- Are you over 40 ?

- Do you smoke or have you smoked in the past?

- Do you get out of breath?

- Do you cough several times a day most days, especially in the winter?

- Are you coughing up phlegm in the morning? If you have answered yes to 2 or more of these questions it is important for you to see your doctor.

Your doctor may take some tests or send you to a lab for a simple breathing test to check how well your lungs breathe air in and out. This is known as a spirometry test.

Many people only discover they have COPD when they need to go into hospital because their symptoms suddenly become much worse. If you have COPD symptoms, being diagnosed as early as possible can reduce the need for hospital treatment (exacerbations) and improve your quality of life.

It is also important if you are affected by and/or are treated for other chronic diseases, e.g. hypertension, heart failure, diabetes, atrial fibrillation, ischemic heart disease, since appropriate treatment of these comorbidities is crucial for optimal management of COPD as well. 


\section{Act}

Training and exercise are essential components in the therapeutic program of the COPD patient; pulmonary rehabilitation improves symptoms such as dyspnea and quality of life, and has an excellent cost/ effectiveness profile in COPD patients. Education should always be part of the rehabilitation program: your doctor may help you feel less breathless, cough less and keep active. Managing COPD effectively can also help you avoid going or returning to hospital.

This can involve lifestyle changes such as gentle exercise to improve your breathlessness and your fitness and activity levels. Although it can be very difficult to do, quitting smoking will reduce further damage to your lungs.

As far as drugs are concerned, the most common way of delivering drugs to treat COPD is in inhaler form. Inhalers allow drugs to be delivered directly to your lungs. There are long-acting bronchodilators that are used to keep your airways open and help control the symptoms of breathlessness. The doctor can also prescribe inhalers that contain steroids associated with long-acting bronchodilators. They are used to reduce the inflammation of your airways. These inhalers must be taken regularly and are very effective only if used

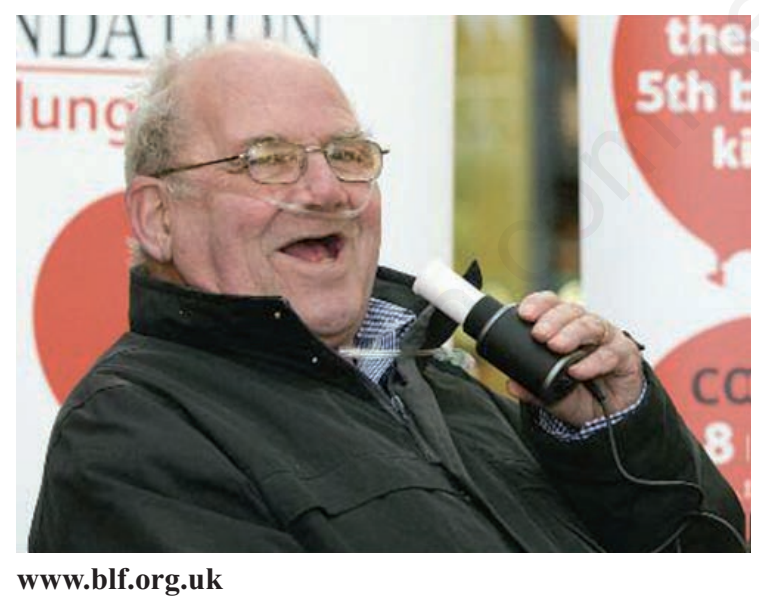

correctly. Make sure you know how to use your inhaler and that you are comfortable using it even when you are very breathless. Different inhalers work in different ways. Each internal medicine ward or clinic has nurses who will be happy to help you with your inhaler technique. It is important that you use your preventer and long-acting reliever inhalers regularly. If you stop taking them, or frequently forget, you will not get the full benefit from your treatment. If you are prescribed more than one inhaler and you have to take them together, pay particular attention. Always have a spare inhaler in case you lose it or it runs out.

\section{Oxygen therapy}

Studies have shown that if you are prescribed breathing air with a higher concentration of oxygen you will stress your heart less. It is very important to understand that oxygen will not necessarily relieve breathlessness. You have to be individually assessed to find out if you will benefit from such intervention and how much oxygen you require. If you keep on smoking, there might be issues about providing oxygen. Long-term oxygen is usually given using a concentrator if you just stay at home or liquid oxygen and a stroller if you walk outside.

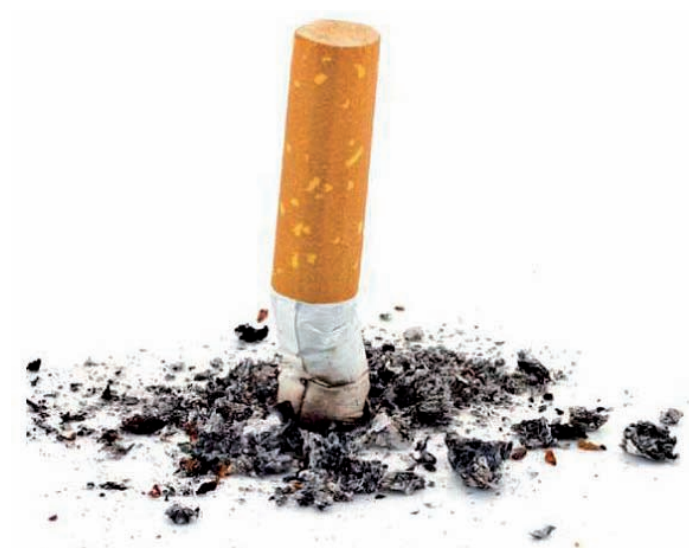

www.lungfoundation.com.au 